\title{
Satellite-Based Mapping of Cultivated Area in Gash Delta Spate Irrigation System, Sudan
}

\author{
Araya Z. Ghebreamlak ${ }^{1, *}$, Haruya Tanakamaru ${ }^{1}$, Akio Tada ${ }^{1}$, Bashir M. Ahmed Adam ${ }^{2}$ \\ and Khalid A. E. Elamin ${ }^{2}$ \\ 1 Graduate School of Agricultural Science, Kobe University, Rokkodai 1-1, Nada, Kobe 657-8501, Japan; \\ tanakam@kobe-u.ac.jp (H.T.); atada@kobe-u.ac.jp (A.T.) \\ 2 Agricultural Research Corporation, P.O. Box 126, Wad Medani, Sudan; bashir70us@yahoo.com (B.M.A.A.); \\ khalidaltaib@yahoo.com (K.A.E.E.) \\ * Correspondence: araiag4@gmail.com; Tel.: +81-080-4768-4782
}

Received: 11 November 2017; Accepted: 23 January 2018; Published: 26 January 2018

\begin{abstract}
In this study, a simple methodology for mapping the seasonal cultivated area of the Gash Delta Spate Irrigation System based on satellite images was developed. The methodology combined information from multiple bands to characterize the land surface in terms of spectral indices (e.g., Normalized Difference Vegetation Index (NDVI), and surface temperature (Ts)). Visual interpretations of a conveniently selected image were undertaken to identify and select sample points of interest. The NDVI and Ts values (computed from multi-date images that represented the crop growing period) of the sample points were used to developed typical NDVI and Ts plots. By analyzing these plots and the cropping calendar, an NDVI and Ts threshold-based algorithm was developed to extract the cultivated area of a given season. Analysis of the developed algorithm showed that it was simple, easily modifiable, and had interpretable rules and threshold values. Comparing the extracted cultivated area with the field report area showed a promising application of the methodology to map and estimate the cultivated area from only remote sensing data.
\end{abstract}

Keywords: spate irrigation; Landsat-7 ETM+; Gash Delta; NDVI; classification algorithm

\section{Introduction}

As competition for water increases and commitments for sustainable ecosystems grow, an increasing awareness has been observed in recent times for making the best use of water, a scarce and valuable resource for all economic activities [1,2]. Irrigated agriculture, which produces approximately $40 \%$ of the world's production, consumes about $70 \%$ of the world's total available freshwater [3]. Irrigation practices can play a significant role in agricultural production to meet the projected food demand in several parts of the world by maintaining or increasing crop yields under changing climatic conditions. As a result, accurate information on irrigated agricultural water use, and its spatial extent and variation, is essential for water resource and crop productivity assessments [4]. One type of information that requires accurate estimation is the acreage of an irrigation system. It is an important input parameter for many irrigation performance indicators such as water use, water productivity, water rights, impact assessment, and performance diagnosis, among others [5]. Despite their importance in estimating irrigation performance indicators, irrigation system data including irrigated/cultivated area are seldom measured in a regular and reliable manner to cover the entire irrigation system. According to [6], the lack of proper and effective management of irrigation systems is related to the conventional method of data collection through field observation, which is difficult, time-consuming, and inadequate in temporal and spatial coverage.

The advancement of satellite technology in terms of spatial, temporal, spectral, and radiometric resolution offers an opportunity to capture the agricultural information of a large area at frequent 
intervals [7-9]. Satellite observations provide reliable, economical, and synoptic data of the Earth's surface. It has been able to provide information with varying degrees of success and accuracy on: crop types [10,11], yield [12,13], and evapotranspiration [14,15]. Remote sensing techniques have also become a viable option and are extensively used for mapping irrigated/cultivated areas [16-21]. Ozdogan et al. [22] provided a thorough review of the sensors (e.g., Moderate Resolution Imaging Spectroradiometer (MODIS), Satellite Pour l'Observation de la Terre (SPOT), Land remote-sensing Satellite (LANDSAT), etc.) and methods used for mapping irrigated/cultivated areas at local, regional, continental, and global scales.

At a local scale, the most common mapping methods are visual interpretation and the digital classification of single or multi dated images [22]. The most commonly used methods of the latter method include multi-stage classification, unsupervised clustering, density slicing, and decision tree classification. Most of the digital image classification approaches depend on statistical similarities to a predefined set of conditions based on observations or existing maps. The requirement of enormous amounts of training and ancillary data makes these methods of classification impossible from remote sensing data alone [23]. Moreover, these methods depend on the magnitude and temporal evolution of spectral vegetation indices derived from red and near infrared reflectance $[8,19]$. However, some studies [24-27] have shown the potential of the combined analysis of spectral vegetation indices with surface temperature observations for studying surface energy exchange processes. A simple and completely remote sensing based land cover classification scheme was proposed by [23]. They employed the seasonal dynamics of the Normalized Difference Vegetation Index (NDVI) and surface temperature to characterize different land cover types such as barren, shrub, forests, water, crops, and others. We adopted their classification logic, with necessary modifications, to develop a methodology to extract the seasonal cultivated area of the Gash Delta Spate Irrigation System from remotely sensed data.

The methodology deals with visual interpretation and spectral and thermal analysis of carefully selected Landsat-7 Enhanced Thematic Mapper Plus (ETM+) images that fall within the given season. This analysis, plus information on the cropping calendar, was focused on developing a simple and easily modifiable and interpretable threshold-based algorithm to extract the cultivated area. That is, although there are voluminous remote sensing-based indices and classification approaches, in this study, however, we sought to develop a methodology that was simple and intuitive for the target users. In doing so, the main objective of the study was to investigate the capability of visual interpretations of a conveniently selected satellite image in identifying and selecting sample points and the importance of combining the spectral and thermal information in uniquely characterizing the land cover of the study area.

\section{Study Area and Data}

\subsection{Study Area}

The Gash Delta Spate Irrigation System (GDSIS), with a net command area of 100,000 ha, is located in Kassala State, Sudan, close to the border with Eritrea (Figure 1). It is an oasis in a surrounding desert with relative humidity ranging from $20-50 \%$, annual rainfall from 180-280 mm (from Hadaliya to Kassala), and an average temperature from $26^{\circ} \mathrm{C}$ in winter to $42{ }^{\circ} \mathrm{C}$ in summer [28]. 


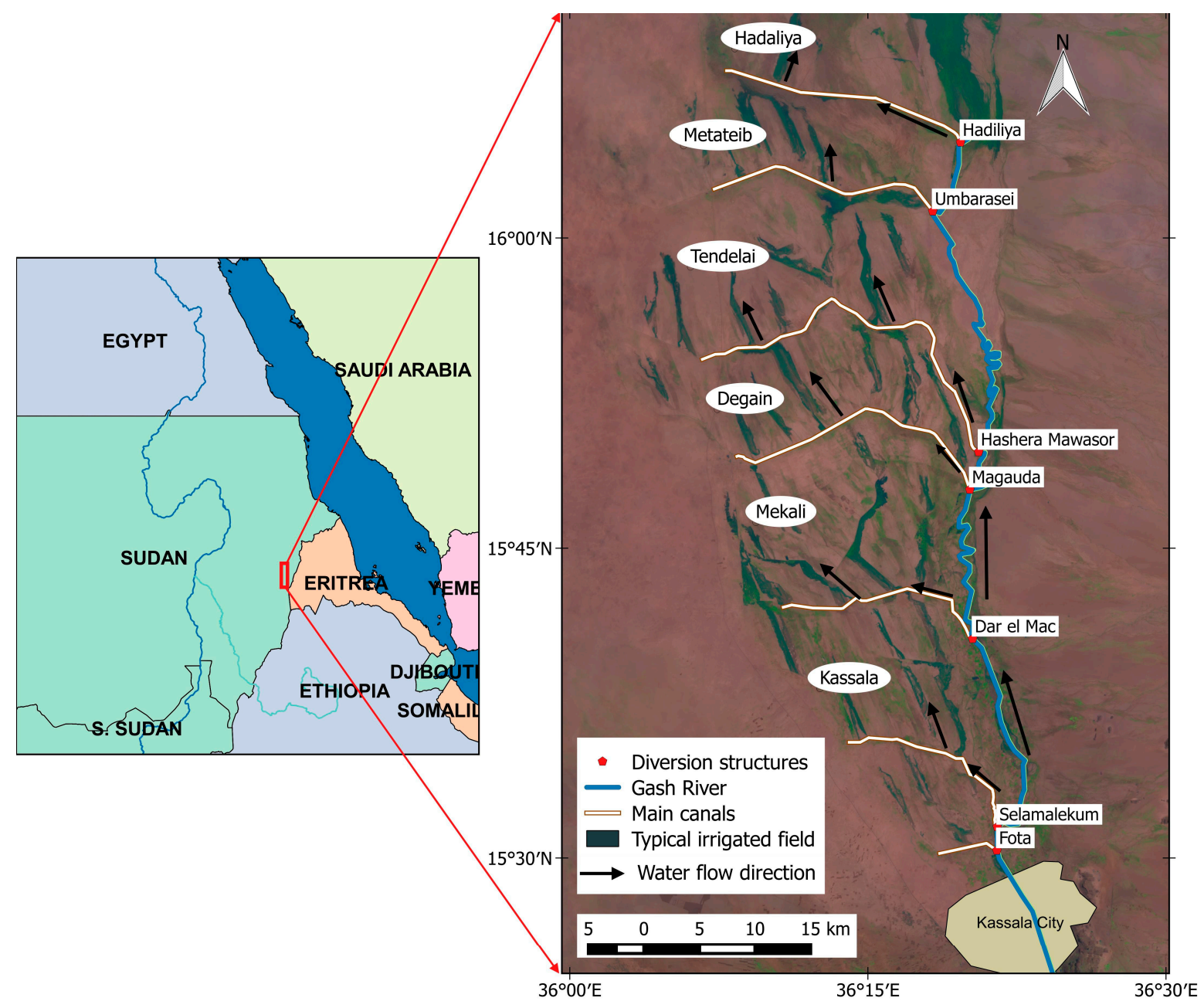

Figure 1. Location and layout of the Gash Delta Spate Irrigation System (GDSIS) (note: the typical irrigated area in this figure shows only the area irrigated up to 28 July 2009 of the 2009-2010 season).

The total command area of GDSIS is divided into six irrigation blocks: Kassala, Mekali, Degain, Tendelai, Metateib, and Hadaliya. Each block is further divided into a number of irrigation units known locally as "Misga". Annually, about one-third of the total Misgas are planned for irrigation and subsequent cultivation, while the remaining two-thirds are fallow for that particular season. Every season, land preparation, which involves clearing of mesquite (Accacia proposes, a thorny and evergreen tree), land leveling, and routine maintenance activities, is carried out before the onset of the flood. Then, floodwater from the west bank of the Gash River is diverted through seven diversion structures for an effective period of 60 to 70 days and conveyed by a system of canal networks to the prepared Misgas, in two turns. That is, the total Misgas to be irrigated in any one year are divided into two parts. These are known as the first and second turns, and irrigation does not begin on the second turn until that on the first turn has been completed [29]. In planning the Misga turns for the first and second turns, it has been assumed that the first flood (mid-July to mid-August) is stronger than the second flood (mid-August to mid-September), thus, $60 \%$ of the area to be irrigated that year is planned for the first turn. The portion of the prepared Misga that received water within the irrigation period (July-September) is referred to as the irrigated area. Usually, about one week after irrigation, when tractors can enter the field, seed sowing is done on the portion of the irrigated area that has been sufficiently watered and adequately prepared. The area that is actually sown with seed is referred to 
as the cultivated area [30]. The dominant crop in GDSIS is a sorghum variety called Aklamoy and is cultivated between September and February.

\subsection{Data}

The primary data used in this study were Landsat-7 ETM+ images. A total of 14 (seven for each season (2009-2010 and 2004-2005)) Landsat-7 ETM+ images were used for the algorithm development. In each season, one of the images was within the irrigation period, while the remaining six were within the crop growing period. These gap-present (scan line corrector (SLC)-off) images were downloaded from the United States Geological Survey (USGS) Global Visualization Viewer (http:/ / glovis.usgs.gov). The selection of this data product was justified by the following reasons. First, Landsat-7 ETM+ has a relatively high spatial and temporal resolution. Second, the location of the case study was within the center of the image where the data quality was very similar to the SLC-on Landsat-7 ETM+ data. In addition, Google Earth was utilized to delineate block boundaries and to supplement the identification of sample points. Finally, field reported data on cultivated areas compiled by [30] were used to compare the results of the developed method.

\section{Methods}

The focus of this study was to develop a simple satellite remote-sensing based algorithm for mapping and estimating the cultivated area of GDSIS. The methodology consisted of four main steps: (1) the preparation and enhancement of satellite images; (2) the visual interpretation of the original and enhanced images to identify and select sample points; (3) building the threshold-based classification algorithm; and (4) testing the applicability of the methodology and the algorithm. Figure 2 depicts the flow chart of the process and the evolution of the satellite image through each process in this study.



Figure 2. Flow chart of the proposed methodology to map the cultivated area of the Gash Delta Spate Irrigation Scheme from the Landsat image (* irrigation period is roughly from mid-July to mid-September). NDVI = Normalized Difference Vegetation Index; Ts = Surface Temperature; MNDWI = Modified Normalized Difference Water Index. 


\subsection{Image Preparation and Enhancement}

In this paper, image preparation dealt with (1) acquiring and organizing the satellite images, (2) selecting the bands and pre-processing, and (3) the visual and spectral enhancement of images. Owing to the availability of field data for verification of the results of the proposed methodology, the search for cloud free Landsat 7-ETM+ images was limited from 2004 to 2011. The 2009-2010 season was found to have many and almost evenly distributed images across the cropping season. Eventually, this season was selected to build the algorithm. A satellite image acquired on 28 July 2009 fell within the irrigation period, while all the other images were within the crop growing period. Bands 1 to 6 from the single-date image (28 July 2009) and 3, 4, and 6 from the other images were selected and processed for the production of visually and spectrally enhanced images. Landsat-7 ETM+ sensors capture reflected solar energy, convert these data to radiance, then rescale these data into an 8-bit digital number (DN) with a range between 0-255. The optical and thermal DN values were converted to the reflectance and land surface temperature (Ts), respectively, by applying the procedure explained in [31].

Spectral enhancement was performed by computing the relevant vegetation and water spectral indices. In the GDSIS, flood water from the Gash River is diverted to each prepared Misga for about three weeks within the irrigation period (mid-July to mid-September). This practice leaves the irrigated area covered with water or wet enough to be clearly detected on a satellite image acquired within this period. Hence, the Modified Normalized Difference Water Index (MNDWI) proposed by [32] was adopted to identify the typical irrigated area. It is the normalized ratio of green $(G)$ and middle infrared (MIR) bands and is expressed as:

$$
\text { MNDWI }=\frac{G-(M I R)}{G+(M I R)}
$$

This index is designed to (1) maximize the reflectance of water by using green wavelengths; (2) minimize the low reflectance of MIR by water features; and (3) take advantage of the high reflectance of MIR by vegetation and soil features. As a result, water features have positive values and are enhanced, while vegetation and soil features usually have zero or negative values and are, therefore, suppressed [32].

The vegetation spectral index used in this study was the Normalized Difference Vegetation Index (NDVI). It is the normalized ratio of near infrared (NIR) and red (R) bands, which are the most sensitive to the vegetation, and is expressed as:

$$
\mathrm{NDVI}=\frac{(\mathrm{NIR})-\mathrm{R}}{(\mathrm{NIR})+\mathrm{R}}
$$

\subsection{Identification and Selection of Sample Points}

Most studies that involve the classification of satellite images start with the collection of sample points for training the classification algorithm and validating the result. Generally, these sample points have to be collected by field survey at the same time as the satellite image acquisition [17]. This often constitutes the largest cost of the mapping project. However, when the mapped features are evidently identified from the background environment, photo-interpretation can substitute the costly field survey [33]. Hence, in this study, visual interpretation of the image was employed to identify irrigated, dry-bare, and forest areas. Due to the specific nature of the GDSIS, images during the irrigation period (or before sowing) were suitable for identifying the above features. Accordingly, the Landsat-7 ETM+ image on 28 July 2009 was selected for this purpose. The image was then processed to produce the standard false color, pseudo natural color, NDVI, and MNDWI maps. Finally, the above maps were visually interpreted to identify and select sample points of irrigated, bare-dry, and forest areas. 


\subsection{Building the Classification Algorithm}

The goal of this study was to develop a simple land cover classification algorithm to extract the seasonal cultivated area of the GDSIS. First, NDVI and surface temperature (Ts) plots of all the sample points identified and selected by visual interpretation were produced to study the temporal dynamics of crop condition across a season. These plots, plus knowledge of the irrigation and cropping calendar, were then used to manually calibrate the classification algorithm. That is, the required variables and their corresponding thresholds of the classification were set based on the NDVI and Ts temporal evolutions of the selected sample points in conjunction with temporal information on crop planting, maturity, and harvest. Nemani and Running [23] established a conceptual diagram showing the seasonal trajectories of different land cover types in the Ts-NDVI space. In this study, we developed a similar Ts-NDVI space of the selected sample points.

\subsection{Verification of Results}

Due to the lack of ground truth data on the cultivated area, we relied on the field report data of the cultivated area for verification of the methodology. First, the developed algorithm was validated by comparing the cultivated area from the developed method with the field reported data. Second, the whole process was repeated for another season. Although the field reported data on the cultivated area were available for all six irrigation blocks, the most northern irrigation block (Hadaliya) was excluded from the analysis as it was very difficult to delineate it from the available irrigation network maps. Unlike the other five irrigation blocks, which are bordered by two main canals (one from the south and the other from the north), in the Hadaliya block, there is only one main canal to its south (Figure 1). The lack of a main canal to its north and the disappearing of the Gash River near the Hadaliya block made it difficult to clearly delineate it from Google Earth.

\section{Results and Discussion}

\subsection{Identification and Selection of Sample Points}

Visual interpretation of a conveniently selected image was done to confidently identify and select the pixels of interest. Figure 3 depicts the identification and selection of sample points of interest from the pseudo natural color, MNDWI, and NDVI maps. In the pseudo natural color map, the flooded area (flooded due to irrigation, hereafter referred as irrigated area) is shown as dark-blue, forest as green, and dry-bare area as brown. As expected, the MNDWI and NDVI enhanced the presence of water (flooded surface) and vegetation, respectively. In both images, white is high value and black is low value. The very sharp MNDWI image indicated a very high moisture difference in the GDSIS during the irrigation period. This proved the potential of employing MNDWI to identify typical irrigated areas. Although the pseudo natural color, MNDWI, and NDVI maps showed a distinction between the irrigated, bare-dry, and forest areas, information from standard false color and Google Earth were also used to increase the confidence of identifying and selecting the sample points of interest.

Considering the analysis of the visual interpretation, one could attempt to estimate or map the seasonal irrigated area. However, as the irrigation period of the GDSIS extends from July to September, irrigated areas irrigated after 28 July 2009 could not be identified from Figure 3. Therefore, extraction and mapping the seasonal irrigated area from only a single image acquired within the irrigation period would be incomplete. Moreover, the aim of this study was to map the seasonal cultivated area, which is usually less than the irrigated area [30], because no sowing of crops takes place on the portion of the irrigated area that: (i) either accumulated too little moisture to supply the total seasonal crop water requirement; or (ii) was not properly prepared for crop cultivation. In other words, in the GDSIS, irrigation is necessary, but not every irrigated area has the sufficient condition for cultivation. Considering the above situation, the selection of typical irrigated areas was done from areas with high MNDWI (high water) and low NDVI (no vegetation or no mesquite infestation). Hence, the selected typical irrigated areas are safely assumed as samples for 
cultivated areas. Accordingly, 150 typical points (50 each) from the irrigated, dry-bare, and forest area were selected and analyzed for the development of an algorithm that extracted the cultivated area. The selection of dry-bare points, as shown in Figure 3, was made outside, but near the GDSIS to avoid any possibility of being irrigated after 28 July 2009.

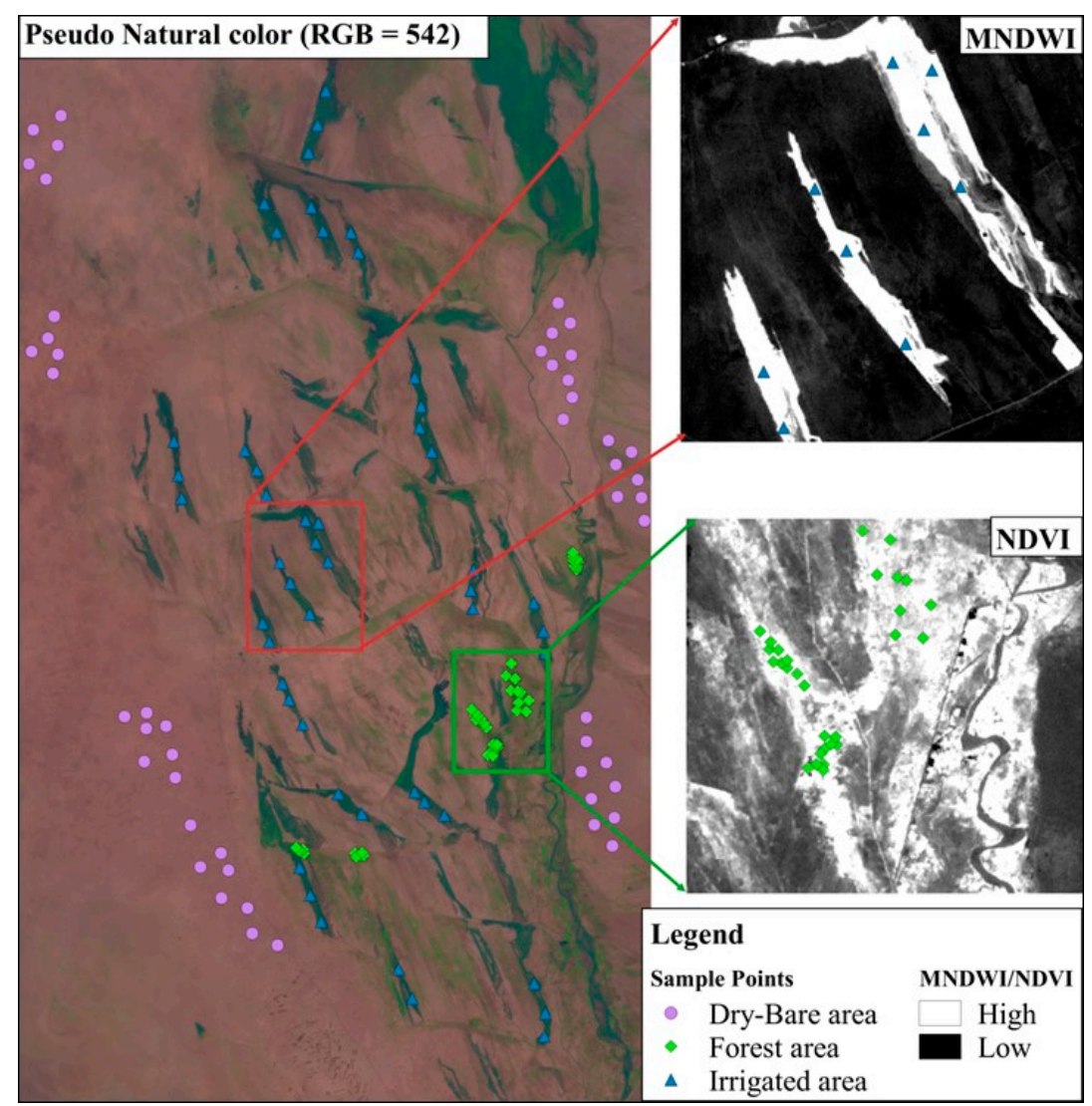

Figure 3. Identification and selection of sample points from visually and spectrally enhanced maps of Landsat-7 Enhanced Thematic Mapper Plus (ETM+) (28 July 2009) of the GDSIS.

\subsection{Building the Algorithm}

Nemani and Running [23] established a conceptual diagram showing the seasonal trajectories of different land cover types in the Ts-NDVI space. In this study, we developed a similar Ts-NDVI space of the selected sample points as shown in Figure 4. As the purpose of this study was to extract the cultivated area in the GDSIS, Figure 4 is derived from the crop growing season in the GDSIS (September to February). Hence, the mean surface temperature and mean NDVI refer to the seasonal mean computed from satellite images within the crop growing period. However, the selection of sample points was done from an image from the irrigation period (in this case, 28 July 2009).

According to [23], forests maintain relatively lower temperature in comparison to crops. Forests - with their deep root systems—-tend to dissipate more energy by transpiration through much of the growing season and, therefore, maintain canopy temperatures close to air temperature. Moreover, forests are aerodynamically rough and can dissipate energy efficiently as sensible heat, therefore, maintaining low surface temperatures. Furthermore, forests generally have higher canopy covers and low fraction of exposed soils, again contributing to low radiometric temperature [23]. On the other hand, crops show a higher surface temperature for two reasons: (1) under low-to-moderate wind speed, crops are aerodynamically smooth when compared to forests, therefore, the high aerodynamic resistances suppress sensible heat transfer, resulting in higher surface temperature; and (2) incomplete canopies through much of the growing season allow more radiation to penetrate and heat the 
underlying soil, thus contributing to high surface temperature. These phenomena can be clearly seen in Figure 4.

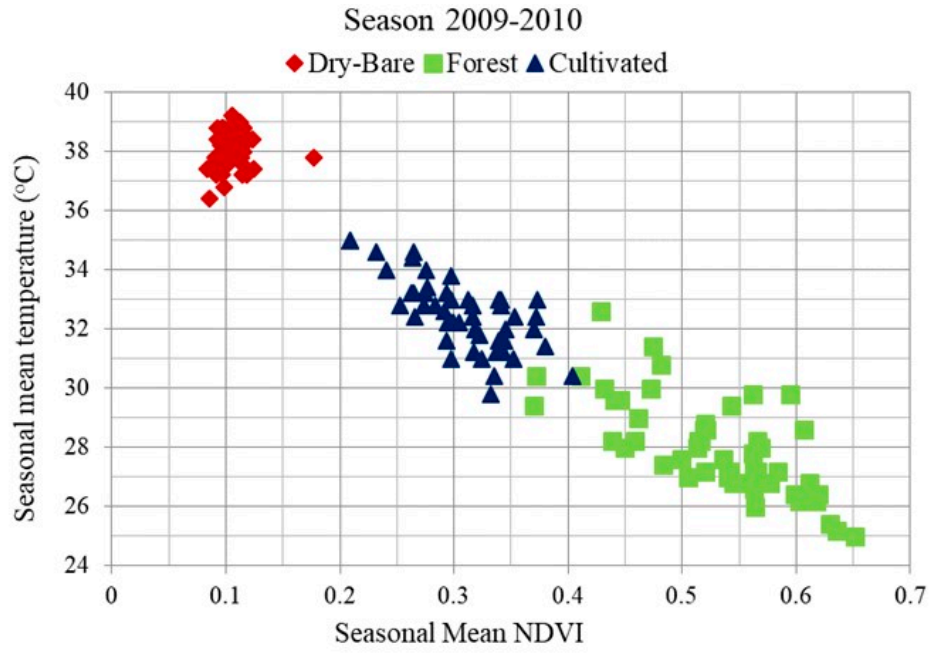

Figure 4. Temperature-NDVI space of the selected sample points (seasonal mean refers to the mean value of each selected point across the growing season depending on the six images (September to February)).

The selected typical dry-bare sample points exhibited a very low NDVI and high Ts. This result was consistent with the study by [23], where they set the threshold value of less than 0.15 mean NDVI and greater than $35^{\circ} \mathrm{C}$ Ts for the barren surface. Therefore, these sample points must be representative of land surface that is neither cultivated nor covered with forest during that particular season.

To investigate the seasonal NDVI and Ts dynamics, the mean values of all the selected pixels in their respective features at each image date were computed and are depicted in Figure 5. As expected, Figure 5a shows that the forest pixels had relatively high NDVI value throughout, even before sowing (e.g., 28 July 2009) and after harvest (e.g., 05 February 2010). As clearly shown in Figure 5b, the forest pixels maintained a relatively low temperature (less than $32{ }^{\circ} \mathrm{C}$ ) throughout the season. Moreover, the variability of NDVI for the forest was lower when compared to that of the crops (cultivated). Hence, the selected forest pixels must be evergreen forests, most likely mesquite trees, which are very dominant in the Gash Delta.

(a)

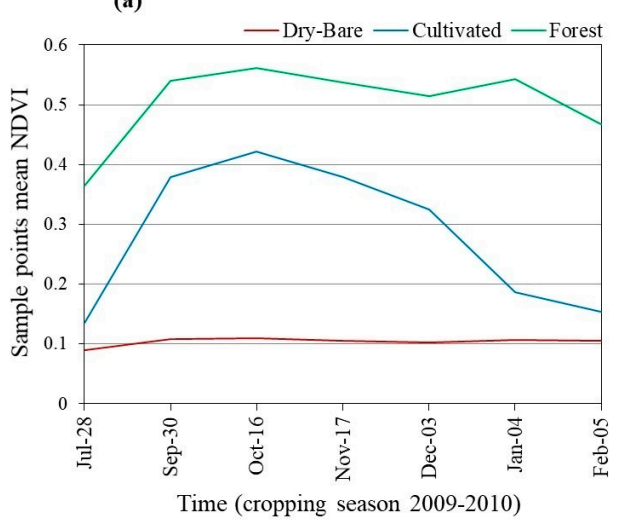

(b)

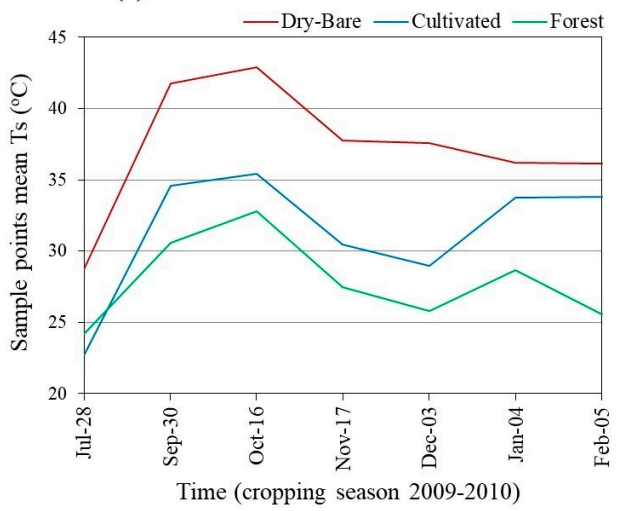

Figure 5. (a) NDVI and (b) surface temperature (Ts) temporal plots of the selected sample points (sample points mean refers to the mean of all the points in their respective feature at the given date). 
On the basis of the above analysis, the threshold-based rule to extract the cultivated area (shown in Figure 6) was developed. Different studies, such as [20,23], have employed many variables (mean, maximum, minimum, range, etc.) derived from many indices. In this study, however, primarily owing to the non-complex land cover of the GDSIS and in search of a simple algorithm, only two variables (mean Ts and NDVI) were found sufficient, as clearly seen in Figure 4. The threshold values of the selected variables were fixed manually from Figure 4. Caution was taken to maximize the inclusion of the cultivated points while minimizing the inclusion from other sample points (Dry-Bare and Forest). Accordingly, an NDVI of 0.2 to 0.4 and Ts of $30-35^{\circ} \mathrm{C}$ were set to best define the region containing the cultivated sample points for the 2009-2010 season. This region was expressed in the form of a decision tree algorithm as shown in Figure 6. The classification decision tree was made to have two simple branches: the first branch, with variables and their corresponding threshold values, produces the cultivated area pixels; and the second branch lumps all the pixels excluded from the first branch as uncultivated.

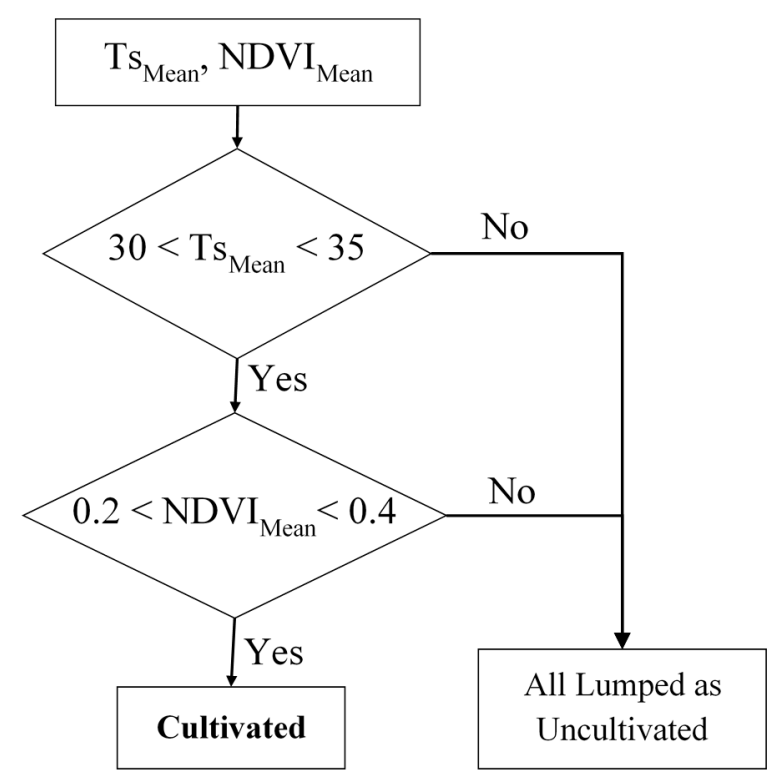

Figure 6. Threshold-based decision tree to extract the cultivated area (2009-2010 season).

In this study, our main purpose was to estimate (extract) the cultivated area, not to classify the land use/cover of the study area. At the same time, the selected land features in Figure 3 do not represent the whole land cover of the study area, but are sufficient for analyzing the seasonal NDVI and Ts dynamics to extract the cultivated area. Therefore, although only the NDVI threshold seemed to suffice in Figure 4, to ensure exclusion of any land cover other than those represented by the dry-bare and forest, adding the Ts threshold was necessary. The upper limit of the Ts, for example, is important in excluding short lived grasses grown in the insufficiently irrigated, hence uncultivated area. On the other hand, the lower limit of Ts was set to exclude, for example, well irrigated areas that were uncultivated due to poor land preparation (infested by trees).

\subsection{Verification}

The algorithm was set in ERDAS IMAGINE 8.4 to map and estimate the total cultivated area of the respective seasons in the GDSIS. The orientation of the cultivated fields (Figure 7) was found to match the orientation of Misgas (local name for irrigation unit) identified from Google Earth and the design layout of the irrigation system network. 


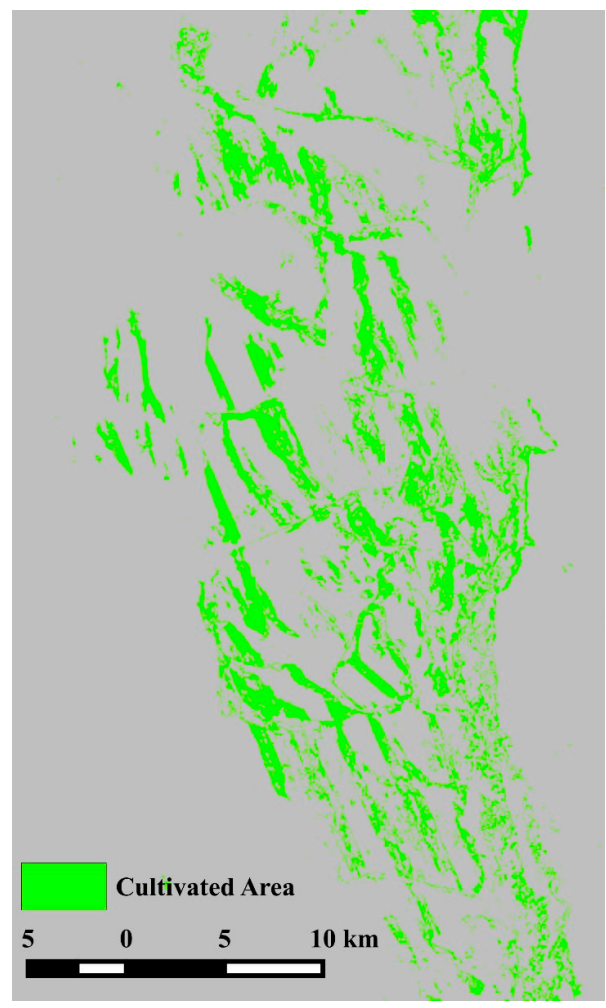

Figure 7. Cultivated area maps using the developed algorithm (2009-2010 season).

To quantitatively assess the accuracy of the algorithm, we compared the extracted cultivated areas with field reported cultivated areas (Table 1). Although we acknowledged the inaccuracies associated with field data, we relied on the cultivated areas reported by [29], which seemed to be the most complete report (detailing the target irrigation area, actual irrigated area, and actual cultivated area for each block from 2004-2011), and hence was considered to be the best available data for verification.

Table 1. Verification results of cultivated area for the 2009-2010 season.

\begin{tabular}{cccccc}
\hline \multirow{2}{*}{ Method of Estimation } & \multicolumn{5}{c}{ Cultivated Area (ha) } \\
\cline { 2 - 5 } & Kassala & Mekali & Degain & Tendelai & Metateib \\
\hline Field report & 5064 & 4876 & 5621 & 5371 & 2924 \\
Remote sensing & 4954 & 4648 & 5845 & 5330 & 3286 \\
Error (ha) & -110 & -228 & 224 & -41 & 362 \\
Error (\%) & -2 & -5 & 4 & -1 & 12 \\
\hline
\end{tabular}

As shown in Table 1, the cultivated areas estimated by the algorithm were very comparable to the field reported cultivated area. The algorithm slightly overestimated the cultivated area for the Degain irrigation block by 224 ha (4\%) and for the Metateib irrigation block by 362 ha (12\%). On the other hand, it marginally underestimated the cultivated areas of the other three irrigation blocks, Kassala by 110 ha (2\%), Mekali by 228 ha (5\%), and Tendelai by 41 ha (1\%). These were in very good agreement, which demonstrates the potential of using remotely sensed data to estimate the cultivated area in the GDSIS.

To test its applicability, the developed approach was repeated for the 2004-2005 season. This season was selected merely on the basis of the availability of many cloud free Landsat-7 ETM+ images. Out of all these images, only the image dated 31 August 2004 fell in the irrigation period and was used for selecting the sample points. This date was near the end of the irrigation 
period, and as a result, sharp MNDWI, pseudo natural, and standard false color images could not be produced. This ultimately affected the quality of the sample data. This can be noted from Figure 8 , where the boundary between the cultivated and forest points are not as clear as those in Figure 4 (2009-2010 season). Although the NDVI and Ts plots showed the same pattern, it also showed the necessity of modifying the threshold values slightly. Accordingly, the threshold values for the 2004-2005 season were set at a mean NDVI of 0.2 to 0.35 and mean Ts of $30-34{ }^{\circ} \mathrm{C}$, as shown in Figure 9. The two cultivated sample points (blue, triangle mark) with a mean NDVI greater than 0.35 were neglected to avoid the inclusion of many sample points from the forest (green, rectangle mark). In other words, a mean NDVI upper limit of 0.35 was more representative of the cultivated sample points than a mean NDVI upper limit of 0.4.

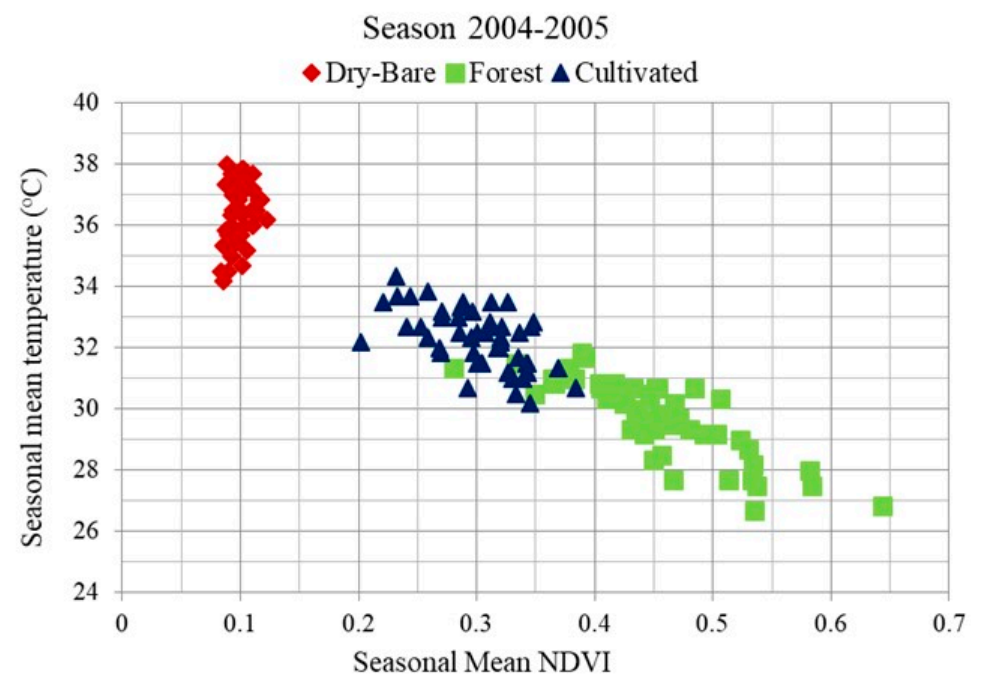

Figure 8. Temperature-NDVI space of the selected pixels from the 2004-2005 season (seasonal mean refers to the mean value of each selected point across the growing season depending on the six images (September to February)).



Figure 9. Threshold-based decision tree to extract the cultivated area (2004-2005 season).

The developed algorithm (Figure 9) was used to extract the cultivated area for the 2004-2005 season and was compared with the field reported cultivated areas as shown in Table 2. The algorithm overestimated the cultivated area of the Kassala irrigation block by $10 \%$ and Mekali 
irrigation block by $20 \%$, whereas it underestimated those of the Degain irrigation block by $12 \%$, Tendelai irrigation block by $19 \%$, and Metateib irrigation block by $25 \%$. Although the errors across all irrigation blocks of the 2004-2005 season were larger than those of 2009-2010, the authors still believe that these errors are reasonably acceptable. The overall good agreement of the estimated cultivated area with the field reported data demonstrates the potential of applying the proposed methodology in the GDSIS.

Table 2. Verification results of cultivated area from the 2004-2005 season.

\begin{tabular}{cccccc}
\hline \multirow{2}{*}{ Method of Estimation } & \multicolumn{5}{c}{ Cultivated Area (ha) } \\
\cline { 2 - 5 } & Kassala & Mekali & Degain & Tendelai & Metateib \\
\hline Field report & 4066 & 3459 & 5397 & 1806 & 2054 \\
Remote sensing & 4485 & 4156 & 4746 & 1471 & 1532 \\
Error (ha) & 419 & 697 & -651 & -335 & -522 \\
Error (\%) & 10 & 20 & -12 & -19 & -25 \\
\hline
\end{tabular}

Assuming that other sources of error were the same for both seasons, the relative poor performance by the algorithm for 2004-2005 was primarily due to the quality of the sample points. As pointed out when setting the threshold values of the algorithm, the quality of the sample points was dependent on the date of the satellite image used for the identification and selection of the sample points. This implies the acquisition of a cloud free satellite image during the irrigation period, from which sufficiently watered areas could be clearly and confidently identified, was necessary for the accuracy of the developed algorithm.

Although the Ts-NDVI space for both seasons showed the same pattern, the resulting threshold values were slightly different. The influence of this small difference was examined by changing the NDVI threshold upper limit for the 2004-2005 season from 0.35 to 0.4 . This change decreased the performance of the algorithm with an error in some of the irrigation blocks as high as $50 \%$. Similar influence was also observed when the Ts threshold upper limit was set at $35^{\circ} \mathrm{C}$ instead of $34^{\circ} \mathrm{C}$. This implies that while the model framework was simple and intuitive, the accuracy of the cultivated area mapping results was highly sensitive to the NDVI and Ts threshold values. Hence, fixing the threshold values using sample points as demonstrated by Figures 4 and 8 was necessary to estimate the cultivated area of each season.

\section{Conclusions}

In this study, satellite remote sensing data were employed to develop a methodology for mapping and estimating the seasonal cultivated area in the GDSIS. Visual interpretations followed by NDVI and surface temperature (Ts) analysis of selected images within the crop period were performed to develop a threshold-based classification algorithm. Due to the specific nature of the GDSIS, the visual interpretations were found to be very effective in selecting sample points. The multi-date image analysis using NDVI and Ts plots of the selected sample points demonstrated the importance and capability of combining information from multiple bands of Landsat-7 ETM+ to uniquely characterize the cultivated area.

Verification of results by comparing the estimated cultivated area with the field reported area demonstrated the capability of the developed algorithm and, hence, the potential of our approach. Moreover, repeating the methodology in a different season proved that the seasonal cultivated area of the GDSIS could be mapped and estimated solely from Landsat-7 ETM+ images. The application of this simple methodology, which requires basic knowledge of remote sensing techniques and uses freely available satellite data, can help the GDSIS management office to regularly estimate the cultivated area at low cost. The main limitation of this study is the use of field reported cultivated area for the verification of results. Moreover, this study focused only on the cultivated area, however, estimation of the seasonal areas that are irrigated but uncultivated due to little water application and estimation 
of uncultivated areas due to poor land preparation are also very important to the management of the system. Therefore, future works should extend the current study to include the above areas and improve the verification process using ground truth data on cultivated areas.

Acknowledgments: This study was supported by the Grant-in-Aid for Scientific Research (B) from the Japan Society for the Promotion of Research (No. 16H04996, HT).

Author Contributions: All authors participated in the field study and obtained qualitative and quantitative information on the study area. Araya Z. Ghebreamlak analyzed the satellite images and wrote the manuscript with Haruya Tanakamaru. Akio Tada, Bashir M. Ahmed Adam and Khalid A. E. Elamin discussed on the paper.

Conflicts of Interest: The authors declare no conflict of interest. The founding sponsors had no role in the design of the study; in the collection, analyses, or interpretation of data; in the writing of the manuscript, and in the decision to publish the results.

\section{References}

1. Van Halsema, G.E.; Vincent, L. Efficiency and productivity terms for water management: A matter of contextual relativism versus general absolutism. Agric. Water Manag. 2012, 108, 9-15. [CrossRef]

2. Haouari, M.; Azaiez, M.N. Optimum cropping patterns under water deficits: Theory and methodology. Eur. J. Oper. Res. 2001, 130, 133-146. [CrossRef]

3. Salmona, J.M.; Friedla, M.A.; Frolking, S.; Wisser, D.; Douglas, E.M. Global rain-fed, irrigated, and paddy croplands: A new high resolution map derived from remote sensing, crop inventories and climate data. Int. J. Appl. Earth Obs. Geoinf. 2015, 38, 321-334. [CrossRef]

4. Alexandridis, T.K.; Panagopoulos, A.; Galanis, G.; Alexia, I.; Cherif, I.; Chemin, Y.; Stavrinos, E.; Bilas, G.; Zalidis, G.C. Combining remotely sensed surface energy fluxes and GIS analysis of groundwater parameters for irrigation system assessment. Irrig. Sci. 2014, 32, 127-140. [CrossRef]

5. Bastiaanssen, W.G.M.; Molden, D.J.; Makin, I.W. Remote sensing for irrigated agriculture: Examples from research and possible applications. Agric. Water Manag. 2000, 46, 137-155. [CrossRef]

6. Ambast, S.K.; Keshari, A.K.; Gosain, A.K. Satellite Remote Sensing to Support Management of Irrigation Systems: Concepts and Approaches. Irrig. Drain. 2002, 51, 25-39. [CrossRef]

7. Atzberger, C. Advances in remote sensing of agriculture: Context description, existing operational monitoring systems and major information needs. Remote Sens. 2013, 5, 949-981. [CrossRef]

8. Mondal, S.; Jeganathan, C.; Sinha, N.K.; Rajan, H.; Roy, T.; Kumar, P. Extracting seasonal cropping patterns using multi-temporal vegetation indices from IRS LISS-III data in Muzaffarpur district of Bihar, India. Egypt. J. Remote Sens. Space Sci. 2014, 17, 123-134. [CrossRef]

9. Bastiaanssen, W.G.M.; Bos, M.G. Irrigation performance indicators based on remotely sensed data: A review of literature. Irrig. Drain. Syst. 1999, 13, 291-311. [CrossRef]

10. Dadhwal, V.; Singh, R.; Dutta, S.; Parihar, J. Remote sensing based crop inventory: A review of Indian experience. Trop. Ecol. 2002, 43, 107-122.

11. Schmedtmann, J.; Campagnolo, M.L. Reliable Crop Identification with Satellite Imagery in the Context of Common Agriculture Policy Subsidy Control. Remote Sens. 2015, 7, 9325-9346. [CrossRef]

12. Bastiaanssen, W.G.M.; Ali, S. A new crop yield forecasting model based on satellite measurements applied across the Indus Basin, Pakistan. Agric. Ecosyst. Environ. 2003, 94, 321-340. [CrossRef]

13. Lobell, D.B. The use of satellite data for crop yield gap analysis. Field Crops Res. 2013, 143, 56-64. [CrossRef]

14. Singh, R.K.; Liu, S.; Tieszen, L.L.; Suyker, A.E.; Verma, S.B. Estimating seasonal evapotranspiration from temporal satellite images. Irrig. Sci. 2012, 30, 303-313. [CrossRef]

15. Liou, Y.; Kar, S.K. Evapotranspiration Estimation with Remote Sensing and Various Surface Energy Balance Algorithms-A Review. Energies 2014, 7, 2821-2849. [CrossRef]

16. Biggs, T.W.; Thenkabail, P.S.; Gumma, M.K.; Scott, C.A.; Parthasaradhi, G.R.; Turral, H.N. Irrigated area mapping in heterogeneous landscapes with MODIS time series, ground truth and census data, Krishna Basin, India. Int. J. Remote Sens. 2006, 27, 4245-4266. [CrossRef]

17. Alexandridis, T.K.; Zalidis, G.C.; Silleos, N.G. Mapping irrigated area in Mediterranean basing using low cost satellite Earth Observation. Comput. Electron. Agric. 2008, 64, 93-103. [CrossRef]

18. Pervez, M.S.; Brown, J.F. Mapping Irrigated Lands at 250-m Scale by Merging MODIS Data and National Agricultural Statistics. Remote Sens. 2010, 2, 2388-2412. [CrossRef] 
19. Gumma, M.K.; Thenkabail, P.S.; Hideto, F.; Nelson, A.; Dheeravath, V.; Busia, D.; Rala, A. Mapping Irrigated Areas of Ghana Using Fusiion of $30 \mathrm{~m}$ and $250 \mathrm{~m}$ Resolution of Remote-Sensing Data. Remote Sens. 2011, 3, 816-835. [CrossRef]

20. Pervez, M.S.; Budde, M.; Rowland, J. Mapping irrigated areas in Afghanistan over the past decade using MODIS NDVI. Remote Sens. Environ. 2014, 149, 155-165. [CrossRef]

21. Gallego, F.J.; Kussul, N.; Skakunb, S.; Kravchenko, O.; Shelestov, A.; Kussul, O. Efficiency assessment of using satellite data for crop area estimation in Ukraine. Int. J. Appl. Earth Obs. Geoinf. 2014, 29, 22-30. [CrossRef]

22. Ozdogan, M.; Yang, Y.; Allez, G.; Cervantes, C. Remote Sensing of Irrigated Agriculture: Opportunities and challenges. Remote Sens. 2010, 2, 2274-2304. [CrossRef]

23. Nemani, K.; Running, S. Land cover characterization using multitemporal red, near-IR and thermal-IR data from NOAA/AVHRR. Ecol. Appl. 1997, 7, 79-90. [CrossRef]

24. Lambin, E.F.; Ehrlich, D. The surface temperature-vegetation index space for land cover and land-cover change analysis. Int. J. Remote Sens. 1996, 17, 463-487. [CrossRef]

25. Karnieli, A.; Agam, N.; Pinker, R.T.; Anderson, M.; Imhoff, M.L.; Gutman, G.G.; Panov, N.; Goldberg, A. Use of NDVI and Land Surface Temperature for Drought Assessment: Merits and Limitations. J. Clim. 2010, 23, 618-633. [CrossRef]

26. Julien, Y.; Sobrino, J.A.; Mattar, C.; Ruescas, A.B.; Jiménez-Muñoz, J.C.; Sòria, G.; Hidalgo, V.; Atitar, M.; Franch, B.; Cuenca, J. Temporal analysis of normalized difference vegetation index (NDVI) and land surface temperature (LST) parameters to detect changes in the Iberian land cover between 1981 and 2001. Int. J. Remote Sens. 2011, 32, 2057-2068. [CrossRef]

27. Sinha, S.; Sharma, L.K.; Nathawat, M.S. Improved Land-use/Land-cover classification of semi-arid deciduous forest landscape using thermal remote sensing. Egypt. J. Remote Sens. Space Sci. 2015, 18, 217-233.

28. Bashier, E.E.; Adeeb, A.M.; Ahmed, H.M. Assessment of water users associations in Spate Irrigation Systems: Case Study of Gash Delta Agricultural Corporation, Sudan. Int. J. Sudan Res. 2014, 4, 109-126.

29. Swan, C. The Recorded Behaviour of the River Gash in Sudan; Ministry of Irrigation and Hydro-electric Power: Khartoum, Sudan, 1959.

30. Anderson, I.M. The Easter Sudan Rehabilitation and Development Fund: GAS Phase II-Design Mission; Technical Paper on Main Findings and Recommendations; The Easter Sudan Rehabilitation and Development Fund (ESRDF): Kassala, Sudan, 2011.

31. Chander, G.; Markham, B.L.; Helder, D.L. Summary of current radiometric calibration coefficients for Landsat MSS, TM, ETM+, and EO-1 ALI sensors. Remote Sens. Environ. 2009, 113, 893-903. [CrossRef]

32. $\mathrm{Xu}, \mathrm{H}$. Modification of normalized difference water index to enhance open water features in remotely sensed imagery. Int. J. Remote Sens. 2006, 27, 3025-3033. [CrossRef]

33. Koutsias, N. An autologistic regression model for increasing the accuracy of burned surface mapping using Landsat Thematic Mapper data. Int. J. Remote Sens. 2003, 24, 2199-2204. [CrossRef] 